\title{
Social Annotation, Critical Literacy, and Justice-Directed Educator Learning
}

Preprint of conference proceeding for publication in Proceedings of the 2021 Society for Information Technology \& Teacher Education International Conference.

Please cite as:

Kalir, J. (in press). Social annotation, critical literacy, and justice-directed educator learning. Paper to appear in Proceedings of the 2021 Society for Information Technology \& Teacher Education International Conference.

Correspondence concerning this preprint should be addressed to:

Jeremiah H. Kalir

University of Colorado Denver

School of Education and Human Development

1380 Lawrence St., Suite 645

Denver, CO 80204

(303) 315-0034

remi.kalir@ucdenver.edu 


\title{
Social Annotation, Critical Literacy, and Justice-Directed Educator Learning
}

\author{
Jeremiah H. Kalir \\ University of Colorado Denver \\ United States \\ remi.kalir@ucdenver.edu
}

\begin{abstract}
This paper/award presentation is shared on behalf of the Marginal Syllabus leadership team having received the 2020 National Technology Leadership Initiative Award, presented by the English Language Arts Teacher Educators group of the National Council of Teachers of English. Annotation is first introduced as a familiar yet often underappreciated practice in literacy education. Second, the social and critical qualities of annotation are briefly reviewed, with attention to the benefits of social annotation for students' literacy learning and critical social annotation as a means by which literacy teacher educators can foster close reading and collaborative discussion about equity-oriented topics. Third and finally, the Marginal Syllabus is introduced and discussed. The Marginal Syllabus is a project that leverages critical social annotation for public conversation about education equity. Since 2016, the Marginal Syllabus has advocated for and productively advanced justice-directed educator learning and critical literacy education.
\end{abstract}

\section{"In the Margins We Found a Place for That to Matter"}

I recently spoke with some teacher education colleagues about their experiences teaching online and learning alongside other educators during the summer of 2020. At the time, trauma from dual pandemics - the COVID-19 public health crisis as well as protests for racial and social justice-influenced how my colleagues, like many teacher educators, sought meaningful ways to connect and converse with their pre-service and in-service colleagues. Amidst uncertainty and exhaustion, summer coursework became a timely opportunity for teacher educators to model meaningful social connection despite physical distance. Moreover, some teacher educators approached this moment as an opportunity to embrace modes of digital learning that facilitated consequential conversation about educational equity and justice.

A few of my colleagues shared with me how they leveraged the social and critical affordances of annotation, as well as resources made available by the Marginal Syllabus project, to further the work of enacting more justice-directed teaching and learning. To honor their efforts, and to amplify the expertise of educators during a moment of ongoing challenge and possibility, I begin by quoting at length from these informal, collegial reflections. Here, for example, is how one literacy teacher educator described her design of writing course:

I had teachers from all over. I had K-12 teachers, university teachers, community college, private tutors. They all brought this shared sense of concern and panic after the spring of 2020 and everything shutting down. Also, within a week of our class starting, George Floyd was killed. So the focus on equity was very sharpened, racial equity in particular. And I knew that, as the instructor, we really had to get this right this summer. One of the ways that I tried to do this was really to focus in on the values of connected learning and to use annotation. As I have taught over the many years, I've always included online annotation, [it] has been very exciting to me. And I always include it as a way to demonstrate that you can be social and participatory online, and you can work in these asynchronous ways. However, this summer, I really wanted to make sure that equitable was meshed into the social and participatory things that we were doing. And so I went to the Marginal Syllabus and I curated a set of readings.

And a second teacher educator mentioned to me his redesigned curriculum theory course: 
I revamped the entire class - new articles, edgy articles that pushed critical thinking, and most of them were from the Marginal Syllabus... [learners] were able to come together in these texts, about very deep issues, against a very heavy social context, and they were able to ping off of each other and have their ideas grow generatively off of each other. This is not the dreaded threaded discussion, you know, like 'Tuesday you need a 500-word post and then respond to three people by Friday.' That's not human, that's not real. Hypothesis flips that script. It's rich, it's not thin. It's inside the text, it's not outside the text. It's annotation and collaboration that happens together, not alone. And that was exactly what we needed during this time of COVID to dig into these deep issues. And with a population of teachers who have been told that they're quasi-teachers, that their expertise doesn't matter. But in the margins we found a place for that to matter in a formative way where we can give each other feedback and grow.

This paper/award presentation is both inspired by and intended to extend the pedagogical creativity and justice-directed commitments evident in the recollections of these teacher educators. Specifically, I will first introduce annotation as a familiar yet often underappreciated practice in literacy education. Second, I will briefly review the social and critical qualities of annotation, with attention to the benefits of social annotation for students' literacy learning and critical social annotation as a means by which literacy teacher educators can foster close reading and collaborative discussion about equity-oriented topics. Third and finally, I will discuss how the Marginal Syllabus, a project that leverages critical social annotation for public conversation about education equity, has advocated for and productively advanced justice-directed educator learning and critical literacy education.

\section{Annotation as Enabling Social and Critical Literacies}

Defined simply, annotation is a note added to a text (Kalir \& Garcia, 2021). As a centuries-old practice, annotation includes the rubrication of medieval manuscripts and also personal marginalia that have thrived for as long as books have been printed (Jackson, 2001; Piper, 2012). In more contemporary contexts, annotation may be synonymous with marks made in textbooks (Marshall, 1997), a practice frequently required of students and, in particular, literacy practices like reading comprehension, textual analysis, and interpretation (i.e. Brown, 2007; Zucker, 2016). Research demonstrates the educational value of annotation for students of various ages, who learn in both online and on-the-ground settings, and who engage with course content and their peers across multiple disciplinary contexts (Zhu, Chen, Avadhanam, Shui, \& Zhang, 2020; Zywica \& Gomez, 2007). Annotation has been, and will continue to be, utilized as an effective instructional strategy in K-12 and post-secondary literacy education (i.e. Allred, Hochstetler, \& Goering, 2020).

Annotation, as academic activity, is frequently associated with digital media and literacy. In particular, social annotation (SA) has emerged as a genre of learning technology that enables the annotation of digital resources for information sharing, social interaction, and the production of new knowledge. Over the past decade, two cross-disciplinary literature reviews about SA and learning (Novak, Razzouk, \& Johnson, 2010; Zhu et al. 2020) have identified a number of key educational benefits. First, SA supports learner sensemaking of domain-specific concepts, methods, and ways of knowing (i.e. Kararo \& McCartney, 2019; Kennedy, 2016). Second, SA enables peer-to-peer knowledge construction activities including elaboration, interpretation, clarification of terms and concepts, conflict among divergent perspectives, and consensus-building (i.e. Plevinski, Weible, \& DeSchryver, 2017). Third, SA is a form of collaborative discourse that "involves coordinated, social processes for learners to identify, communicate, and tackle their learning problems" (Chen, 2019, p. 195). Forth, SA functions as a type of interactive reader response, encouraging emergent and negotiated meaning-making; students, for example, can use SA to "shift among and layer reading lenses to focus on reading for ideas, rhetorical reading, critical reading, and aesthetic reading" (Sprouse, 2018, p. 39). SA situates digital dialogue atop a reading, creating a more proximal and "anchored" (Gao, Zhang, Franklin, 2013) form of online discussion that turns texts into discursive contexts.

As I have argued elsewhere (i.e. Kalir, 2020a), it is beneficial for literacy educators and teacher educators to understand how annotation - and SA in particular - can also enable critical literacies. Annotation is broadly resonant with a Freirian stance toward critical literacy (Freire \& Macedo, 1987), or the idea that reading and writing the word is catalyzed by reading and writing the world. This stance translates seamlessly into contemporary, mediarich contexts in which SA can augment other critical literacy "skills and practices that lead to the creation of digital 
texts that interrogate the world" (Ávila \& Pandya, 2013, p. 3). From a Bakhtinian perspective (1981), languageand whether written or spoken - is understood to be in dialogue with other texts and authors. Annotation exemplifies language as socially situated, with meaning recursively constructed as people write SA in response to, and also contest, other individuals and discourses (i.e. Kalir \& Dean, 2018). Third, annotation can also be written as a counternarrative, or an alternative to conventional methods and a challenge to problematic messages (i.e. O'Hare, 2020). In the words and the multimodal works of artist Alexandra Bell, annotation can make visible and help redress racialized and gendered narratives, and can "tip the scale" toward justice (Hairston, 2017). Indeed, the expansive and expressive possibilities of annotation, and SA, include its role as critical media: "As a resource that may be authored and leveraged across texts and social settings, annotation expresses power on behalf of myriad constituencies and for various ideological ends (Kalir \& Garcia, 2021, p. 115)." Annotation is an everyday literacy practice that is both social and critical, dialogic and multimodal, and that can also advance counternarratives.

A handful of literacy researchers and teacher educators have recognized the importance of bridging critical, equity-oriented learning with the study of SA. This includes explicit concern for critical social annotation (CSA) or annotation that centers marginalized perspectives, promotes discussion across difference, recognizes power in knowledge construction, and opens discursive pathways to subvert inequity (Brown \& Croft, 2020). The importance of CSA to critical literacies is echoed by teacher educators Bali and Caines (2018) who have observed: "Annotation promotes educator agency and has the ability to foster equity-centric dialogue. This approach is inspired by the transformative potential of openness in education, while recognizing that the use of technology for connection still carries implications for politics and equity" (p. 15). Moreover, the justice-directed possibilities of CSA are echoed in Mirra's (2018) commentary about annotation: "I can imagine no greater role for teaching and scholarship than to foster mutual humanization for the purpose of promoting equity and justice. For me, annotation represents one practice that can support us as we continue on that worthy journey" (p. 35). Echoing these scholars' observations about the transformative possibilities of annotation, I now summarize my collaborative efforts extending an equityoriented line of CSA research to enable justice-directed learning for teacher educators and their K-12 colleagues.

\section{The Marginal Syllabus: Critical Social Annotation for Justice-Directed Educator Learning}

Since 2016, the Marginal Syllabus (http://marginalsyllab.us/) has sparked and sustained conversation via CSA about educational equity through collaborative technologies and partnerships. The project's use of the term "marginal" is intentional and representative of multiple interpretations. First, we support educators to engage with marginal perspectives and counternarratives. The Marginal Syllabus positions and supports educators to read, critically annotate, and discuss educational scholarship "that interrogate[s] bias and power, and that work[s] toward greater equity in educational, social, and political contexts" (Kalir \& Dillon, 2019, p. 137). Second, during Marginal Syllabus activities educators discuss focal texts using CSA and their commentary occurs in marginal discursive spaces online that functions as "a marginal space of community formation to blossom public civic thought" (Kalir \& Garcia, 2019, p. 439). A third interpretation of "marginal" concerns a reimagining of what counts as educator professional learning. The Marginal Syllabus inverts conventional, didactic, and atomistic professional development by "pair[ing] the development of new technical skills with ongoing examination of equity topics and tensions- like digital literacy, learner agency, and ethical uses of learning technology - that have affected, and will continue to impact, the lives and learning of students" (Kalir, Cantrill, Dean, \& Dillon, 2020, p. 468). This summary of the Marginal Syllabus draws upon our project's established scholarly record and programming portfolio to describe how educators read and write CSA so as to advance their professional learning about educational equity and justice.

The Marginal Syllabus is possible thanks to many people and organizations who support our work. Five years into our project, we are an established research-practice partnership committed to making public and accessible educational equity conversations, helping to change educators' beliefs and practices, and enacting more just learning futures. We embrace a justice-directed approach to partnership for educational change that scholars like Gutiérrez and Jurow (2016) call a social design experiment. Social design experiments pair "the more traditional aim of design experiments to create theoretically grounded and practical educational interventions [with] the social agenda of ameliorating and redressing historical injustices and inequities, and the development of theories focused on the organization of equitable learning opportunities" (p. 567). The Marginal Syllabus has three long-standing organizational partnerships that help to guide this social design experiment. The National Writing Project (NWP) has, since 2017, provided significant administrative and programmatic support. The National Council of Teachers of English (NCTE) has, since 2018, opened up access to journal articles so that educators can more easily read and discuss equity-oriented scholarship. And the SA organization Hypothesis - whose eponymous and free annotation 
technology is used by hundreds of K-12 schools and higher education institutions-has, since 2016, served as our technological anchor given the use of SA to media educator discourse. Figure 1, below, is screenshot of a representative Marginal Syllabus annotation conversation from the 2019-2020 syllabus which shows an NCTE article, made openly accessible, and annotated using the SA technology Hypothesis.

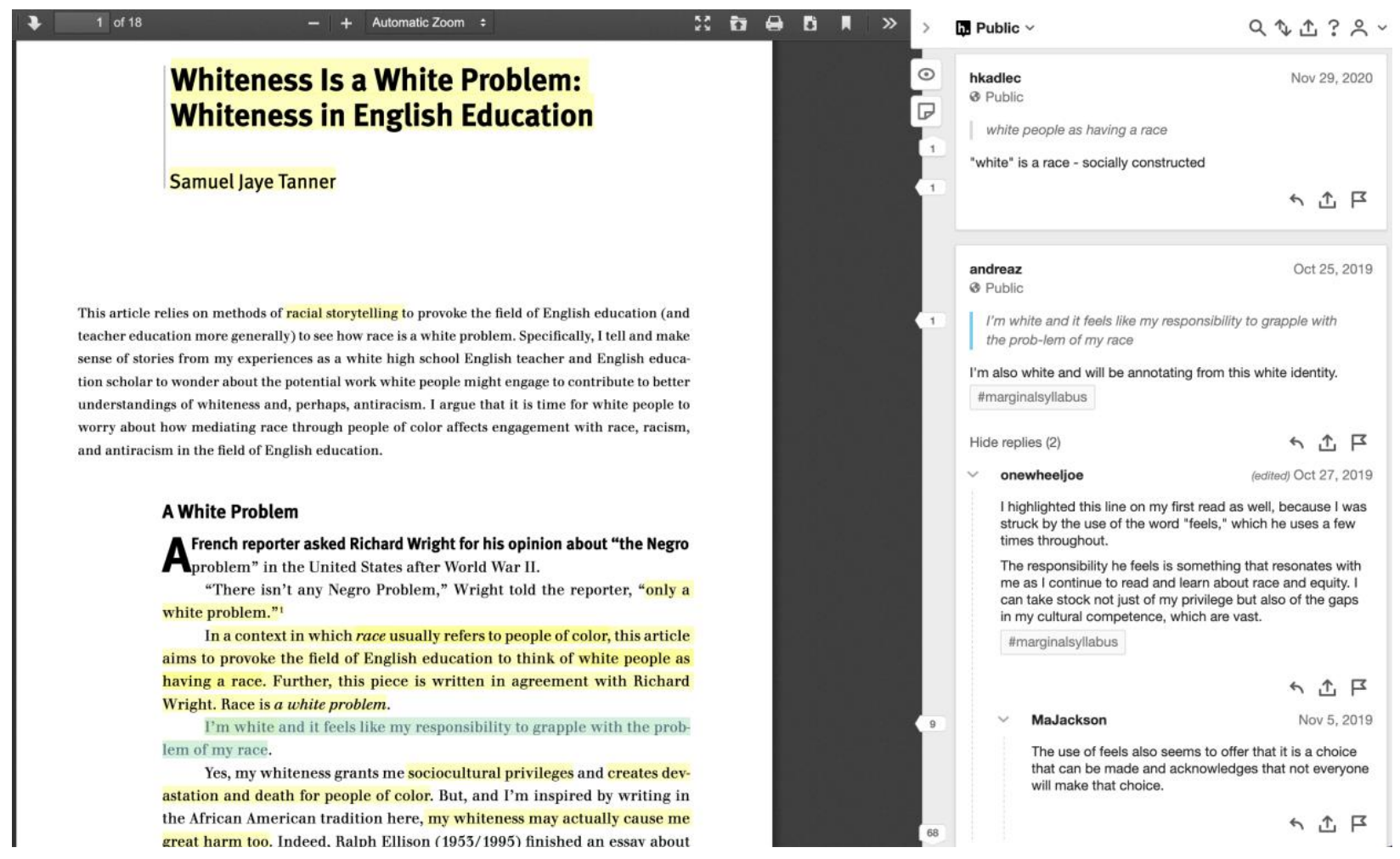

Figure 1: Representative Marginal Syllabus conversation

Complementing the Marginal Syllabus' organizational partnerships are partner authors. Partner authors are K-12 educators, teacher educators, and scholars who - to a person - have provided consent for other educators to publicly annotate their scholarship. To date, 62 partner authors have provided the Marginal Syllabus with permission to feature their writing for others to read, annotate, and discuss. Scholarship by partner authors has been organized into six syllabi, inclusive of 41 texts that serve as equity-oriented discursive contexts. Common themes across Marginal Syllabus texts include critical literacies, culturally relevant and sustaining pedagogies, racial equity in literacy education, anti-racist pedagogy, and youth agency and civic literacies. Over 600 educators have participated in the Marginal Syllabus since 2016, whether through the project's open and public conversations, in coordination with both local NWP sites and open education communities, and in teacher education courses. In doing so, educators have authored more than 4,700 public Hypothesis annotations. This corpus represents a growing public record and open dataset of educators' equity discourse made visible by SA.

As Co-founder and Research Director of the Marginal Syllabus, the overarching goal of our project's scholarship is to document how we have leveraged the educational affordances of CSA in service of educators' justice-directed professional learning. To do so, it is imperative that we advance theoretically grounded and sociocultural approaches to the design of equitable educator learning. Conceptual anchors of our scholarship have included group-level distributed cognition, intersubjective meaning-making (Kalir, 2020b), and critical civic literacies (Kalir \& Garcia, 2019), among other complementary perspectives. The sociocultural stance of our scholarship is appropriately paired with methods of critical analysis to document expansive learning, critique inequity, and transform educational practices. My co-authors and I have used various methods of critical analysis given the multiple sources of data present in our scholarship, and these methods have included critical discourse analysis, social learning analytics, social network analysis, as well as design narrative. Across much of our research, my colleagues and I have looked carefully at discursive threads as a unit of analysis to examine evidence of critical 
social annotation in educators' turns of talk (i.e. Kalir \& Perez, 2019). As educators read together, as they add notes to a text, and as they reply to one another over time, we see evidence of educators drawing upon established SA practices like collaboration, knowledge construction, and meaning-making, and re-directing and repurposing those shared epistemic activities to discuss via CSA educational equity and justice (Kalir, 2020a, Kalir \& Dillon, 2019).

For example, the article "Miles Morales: Spider Man and Reimagining the Canon for Racial Justice" (Worlds \& Miller, 2019), published in NCTE's English Journal, was featured in the 2019-2020 Marginal Syllabus. Nearly two dozen educators have now read, publicly annotated, and discussed this article that calls on literacy educators to critique the racial hierarchies of the literary canon and disrupt the use of canonical texts in literacy curricula. In just the second sentence of the article, Worlds and Miller note that "the canon is a weapon of the colonial project, which perpetuates Eurocentrism and violence against people of color" (p. 43). During a public Marginal Syllabus discussion, that sentence was highlighted by the educator MaJackson who also added her own reader response: "It is hard to get people to see this. Especially if they have always identified with what is centered." The very next sentence has also elicited annotation. Worlds and Miller critique canonical texts, observing how books like "To Kill a Mockingbird and Adventures of Huckleberry Finn, are centered on White characters' experiences learning about racism and/or [that such books] take place in the past: Invisible Man and Black Boy are examples" (ibid). In response, richnovack annotated: "This is such an important realization for teachers to make. Teachers sometimes don't consider the unintentional problems of these texts." Furthermore, the opening paragraph of the article also argues that "while texts associated with the canon certainly have a place in English classrooms, we worry that neglecting contemporary texts that address racism results in students associating racism with the past" (ibid). A note added to this sentence reads, in part: "This is difficult when many interpret longevity in the canon as a mark of quality and not as a component of the colonial/Eurocentric/racist systems that have elevated these texts."

These notes, written and shared publicly by literacy educators during a Marginal Syllabus conversation, exemplify CSA, or notes added to a text that center marginalized perspectives, promote discussion across difference, recognize power in knowledge construction, and open discursive pathways to subvert inequity in literacy education. More generally, research about the Marginal Syllabus suggests that the critical and social qualities of annotation can guide educators to develop anti-racist strategies such as the "will, skill, and capacity to engage in courageous conversations" (Pollock, 2008, p. 343). Our research demonstrates how CSA opens productive discussion about anti-racist pedagogy and raises educator critical consciousness (Kalir et al., 2020). The Marginal Syllabus evidences CSA as collaborative and communal epistemic activity (Kalir, 2020b). Learning technologies - and the practices enabled by such tools - are neither neutral nor apolitical, just as knowledge is neither divorced from sociopolitical context nor bereft of bias. Questions about whose knowledge is valued, and how such knowledge is constructed, must be asked of the technologies that mediate educator learning. Our research suggests CSA can productively tether educators' intersubjective, epistemic knowledge-building with commitments to justice-directed education. The Marginal Syllabus highlights educators reading as a social activity, leaving their marks across texts of pedagogical and political relevance, and sharing their digital wonderings and rough draft thinking with one another as new professional learning pathways.

\section{An Invitation for Annotation}

This paper/award presentation is an invitation. The Marginal Syllabus is a public project and open resource. As of this writing, our team recently announced the 2021 syllabus, featuring four texts from the NCTE journal Research in the Teaching of English written by six partner authors, and aligned with the Black Lives Matter at School Year of Purpose that calls on "educators to reflect on their own work in relationship to antiracist pedagogy and abolitionist practice, persistently challenging themselves to center Black lives in their classrooms" (Black Lives Matter at School, 2020). As a (literacy) teacher educator, you and your colleagues are very welcome to join a public annotation conversation, watch a webinar discussion with partner authors, and also organize your own private annotation group for a course, book club, or research. You are very welcome to also remix prior readings into your course syllabi or watch our partner author webinars with your students. Just as annotation makes visible the social life of texts, so too does the Marginal Syllabus make viable opportunities to leverage the critical and social qualities of annotation for more equitable literacy education across online and on-the-ground contexts. The professional and pedagogical value of annotation only becomes truly re-markable through ongoing partnership, co-design, and participation. And as evidenced in the Marginal Syllabus, CSA - in particular-is a powerful means of writing in community when the purpose of such annotation is shared authorship of professional learning counternarratives. 


\section{References}

Allred, J., Hochstetler, S., \& Goering, C. (2020). "I love this insight, Mary Kate!”: Social annotation across two ELA methods classes - CITE Journal. Contemporary Issues in Technology and Teacher Education, 20(2). $\mathrm{https}$ ://citejournal.org/volume-20/issue-2-20/english-language-arts/i-love-this-insight-mary-kate-social-annotationacross-two-ela-methods-classes

Ávila, J., \& Pandya, J. (Eds.). (2013). Critical digital literacies as social practice: Intersections and challenges. New York, NY: Peter Lang.

Bakhtin, M. (1981). The dialogic imagination. Four essays by M. M. Bakhtin. Austin: University of Texas Press.

Bali, M., \& Caines, A. (2018). A call for promoting ownership, equity, and agency in faculty development via connected learning. International Journal of Educational Technology in Higher Education, 15(1), 46. https://doi.org/10.1186/s41239-018-0128-8

Black Lives Matter at School. (2020). The Year of Purpose. Black Lives Matter at School. https://www.blacklivesmatteratschool.com/year-of-purpose.html

Brown, M. D. (2007). I'll have mine annotated, please: Helping students make connections with texts. English Journal, 73-78.

Brown, M., \& Croft, B. (2020). Social annotation and an inclusive praxis for open pedagogy in the college classroom. Journal of Interactive Media in Education, 2020(1), 8. https://doi.org/10.5334/jime.561

Chen, B. (2019). Designing for networked collaborative discourse: An UnLMS approach. TechTrends, 63(2), 194 201. https://doi.org/10.1007/s11528-018-0284-7

Freire, P., \& Macedo, D. (1987). Literacy: Reading the word and the world. South Hadley, MA: Bergin \& Garvey.

Gao, F., Zhang, T., \& Franklin, T. (2013). Designing asynchronous online discussion environments: Recent progress and possible future directions. British Journal of Educational Technology, 44(3), 469-483.

https://doi.org/10.1111/j.1467-8535.2012.01330.x

Gutiérrez, K., \& Jurow, A. S. (2016). Social design experiments: Toward equity by design. Journal of the Learning Sciences, 25, 565-598.

Hairston, T. (2017, June 9). Alexandra Bell Makes Art for the Fake-News Era. The Cut.

https://www.thecut.com/2017/06/brooklyn-artist-alexandra-ball-racial-bias-new-york-times.html

Jackson, H. J. (2001). Marginalia: Readers writing in books. New Haven, CT: Yale University Press.

Kalir, J. (2020). "Annotation is first draft thinking": Educators' marginal notes as brave writing. English Journal, 110(2), 62-68. https://doi.org/10.35542/osf.io/7wnxq

Kalir, J. (2020). Social annotation enabling collaboration for open learning. Distance Education, 41(2), 245-260. https://doi.org/10.1080/01587919.2020.1757413

Kalir, J., Cantrill, C., Dean, J., \& Dillon, J. (2020). Iterating the Marginal Syllabus: Social reading and annotation while social distancing. Journal of Technology and Teacher Education, 28(2), 463-471.

https://www.learntechlib.org/primary/p/216246/

Kalir, J., \& Dean, J. (2018). Web annotation as conversation and interruption. Media Practice and Education, 19(1), 18-29. https://doi.org/10.1080/14682753.2017.1362168 
Kalir, J., \& Dillon, J. (2019). Educators discussing ethics, equity, and literacy through collaborative annotation. In K. H. Turner (Ed.), The ethics of digital literacy: Developing knowledge and skills across grade levels (pp. 131141). Lanham, MD: Rowman \& Littlefield.

Kalir, J. \& Garcia, A. (2019). Civic writing on digital walls. Journal of Literacy Research, 51(4), 420-443. https://doi.org/10.1177/1086296X19877208

Kalir, J., \& Garcia, A. (2021). Annotation. Cambridge, MA: The MIT Press.

Kalir, J., \& Perez, F. (2019). The Marginal Syllabus: Educator learning and web annotation across sociopolitical texts and contexts. In A. Reid (Ed.), Marginalia in modern learning contexts (pp. 17-58). IGI Global.

Kararo, M., \& McCartney, M. (2019). Annotated primary scientific literature: A pedagogical tool for undergraduate courses. PLOS Biology, 17(1), e3000103. https://doi.org/10.1371/journal.pbio.3000103

Kennedy, M. (2016). Open annotation and close reading the Victorian text: Using Hypothes.is with students. Journal of Victorian Culture, 21(4), 550-558. https://doi.org/10.1080/13555502.2016.1233905

Marshall, C. (1997). Annotation: From paper books to the digital library. In Proceedings of the second ACM international conference on digital libraries (pp. 131-140). New York, NY: ACM Press.

doi:10.1.1.29.2013\&rep=rep1\&type=pdf

Mirra, N. (2018). Pursuing a commitment to public scholarship through the practice of annotation. The Assembly: A Journal for Public Scholarship on Education, 1, 29-36.

Novak, E., Razzouk, R., \& Johnson, T. E. (2012). The educational use of social annotation tools in higher education: A literature review. The Internet and Higher Education, 15(1), 39-49. https://doi.org/10.1016/j.iheduc.2011.09.002

O’Hare, I. (Ed.). (2020). Erase the patriarchy: An anthology of erasure poetry. University of Hell Press.

Piper, A. (2012). Book was there: Reading in electronic times. Chicago, IL: The University of Chicago Press.

Plevinski, J., Weible, J. and Deschryver, M. (2017). Anchored annotations to support collaborative knowledge construction introduction. In Making a Difference: Prioritizing Equity and Access in CSCL, 12th International Conference on Computer Supported Collaborative Learning (CSCL), pp. 111-118.

Pollock, M. (Ed.). (2008). Everyday antiracism: Getting real about race in school. New York, NY: The New Press.

Sprouse, M. L. (2018). Social annotation and layered readings in composition. In The Proceedings of the Annual Computers \& Writing Conference 2018, 39-52.

Worlds, M., \& Miller, H. (2019). Miles Morales: Spider-Man and reimagining the canon for racial justice. English Journal, 108(4), 43-50.

Zhu, X., Chen, B., Avadhanam, R. M., Shui, H., \& Zhang, R. Z. (2020). Reading and connecting: using social annotation in online classes. Information and Learning Sciences, 121(5/6), 261-271. https://doi.org/10.1108/ILS-042020-0117

Zucker, L. (2016). Teaching speaking and listening: Reading closely and discussing meaningfully. English Journal, 105(5), 92-94. JSTOR. https://doi.org/10.2307/26606382

Zywica, J., \& Gomez, K. (2008). Annotating to support learning in the content areas: Teaching and learning science. Journal of Adolescent \& Adult Literacy, 52(2), 155-165. https://doi.org/10.1598/JAAL.52.2.6 